\title{
IMAGEN Y EXPERIENCIA: EL CARNAVAL DE ARICA COMO AUTORREPRESENTACIÓN FESTIVA
}

\author{
IMAGE AND EXPERIENCE: THE CARNIVAL OF ARICA AS FESTIVE \\ SELF-REPRESENTATION
}

\author{
Andrea Chamorro Pérez ${ }^{1}$
}

\begin{abstract}
Tras las migraciones aymara, desde la cordillera de los Andes hacia las ciudades costeras del Norte Grande de Chile, que se iniciaron en la década de 1960; los actores andinos no solo mantuvieron nexos festivos con los lugares de origen, sino que buscaron reactualizar sus manifestaciones expresivas (fiestas, ritos, danzas y música) en los espacios urbanos. En Arica, la preponderacia de estos procesos se manifiesta con vigor en la realización del Carnaval "Inti Ch'amampi, Con La Fuerza del Sol", fiesta que ha demostrado constituir una alternativa de comunicación e interacción social en escenarios heterogéneos; y cuya exploración guía a revisar la invisibilidad y supuesta atemporalidad de los actores andinos.

En este escenario, recogemos el concepto de performance-como vehículo teórico y metodológico-que permite comprender estas prácticas expresivas como estrategias o recursos culturales de comunicación social y simbólica, a través de la cuales los actores andinos buscan autorrepresentarse en un espacio público local y transfronterizo. A la vez que subrayarlas como fenómenos o expresiones corpóreas que permiten transmitir y exhibir los marcos de referencia imagética, estética e identiraria desde la experiencia vivida de sus actuantes: bailarines y bailarinas andinas.
\end{abstract}

Palabras claves: Arica, carnaval andino, performance, imagen y autorrepresentación.

After the Aymara migrations from the Andes mountains to the coastal cities of the Chilean Far North, which started in the 1960s, the Andean actors not only maintained festive links with their places of origin, but they also sought to reenact their expressive manifestations (festivals, rituals, dances and music) in urban areas. In Arica, the prevalence of these processes is manifested strongly in the celebration of the "Inti Ch' amampi, with the strength of the sun" carnival, a celebration that has shown to be an alternative form of communication and social interaction in heterogeneous scenarios, the exploration of which calls for a revision of the invisibility and alleged timelessness of Andean actors. In this scenario, we draw on the concept of performance - as a theoretical and methodological construct-which allows us to understand these expressive practices as strategies, or cultural resources, of social and symbolic communication, through which the Andean actors seek to represent themselves at a local and cross-border public space. At the same time, we underline them as corporeal phenomena or expressions that allow the transmission and display of image, esthetic and identity reference frameworks, from the lived experience of participants: Andean dancers.

Key words: Arica, Andean carnival, performance, image, experience and self-representation.

El "Norte Grande" de Chile, como lo definiera Sabella (1959) apelando a una poética del paisaje y las luchas obreras en la pampa, refiere a la enorme extensión de territorio dominada por el Desierto de Atacama. Espacio que ha devenido en una poderosa metáfora, cuya evocación a las ideas de "vacío" y/o "ausencia", ha acompañado las representaciones sociales y visuales de las poblaciones humanas que habitaron y habitan estas extensiones.

Consecuentemente, Alvarado et al. (2012) observan que las imágenes fotográficas producidas en torno al desierto y altiplano chileno no solo se caracterizan por las reducidas -o casi inexistentesrepresentaciones de las poblaciones indígenas; sino que estas transitan desde la búsqueda de "una estética del desierto y, por extensión, de sus habitantes" (Alvarado et al. 2012:9), donde es el contexto natural o paisaje el principal protagonista; hacia la construcción de un imaginario contemporáneo donde lo central es la exhibición de una ritualidad andina detenida en el tiempo (Alvarado y Möller 2012). De igual forma, Carreño (2005) constata que las estructuras narrativas del cine documental chileno han buscado construir una imagen de los pueblos andinos basándose en una sobrerrepresentación de "fiestas, danzas, vestidos, casas u otros elementos" (Carreño 2005:88). Así como en una apelación a referencias contextuales que remiten a un pasado

1 Departamento de Antropología, Universidad de Tarapacá, Arica, Chile. achamorro@uta.cl

Recibido: marzo 2016. Aceptado: septiembre: 2016.

http://dx.doi.org/10.4067/S0717-73562017005000002. Publicado en línea: 14-marzo-2017. 
remoto (prehispánico) y/o a la simbiosis con el paisaje del desierto.

En torno a esta evidencia, Alvarado et al. (2012) proponen que la tensión: invisibilidad y sobrerrepresentación visual de los pueblos andinos, se asocia a su vinculación sociosimbólica con lo extranjero; vale decir que dado que el "Norte Grande" ingresó tardíamente a la soberanía e historia chilena tras la Guerra del Pacífico (años 1879-1929) ${ }^{1}$, se evitaría referir al "pasado peruano y boliviano, las identidades propias de sus pueblos originarios, su ser altiplánico" (Baez y Castro 2012:83), a riesgo de evocar otros imaginarios nacionales.

No obstante, cabe argumentar que el representar a los pueblos andinos como constitutivos de un "desierto" o paisaje alejado en el tiempo y en el espacio, hace parte de un intento político por legitimar la intervención en un territorio económicamente estratégico que estuvo ligado primero a la industria del salitre y hoy en día a la gran minería del cobre. En este sentido, sugerimos comprender la noción de "desierto" como una "invención" que oculta y valida la empresa colonizadora y capitalista de explotación de los recursos naturales y sus gentes (indígenas, migrantes, pampinos/as, mestizos/as, proletarios/as). A la vez que priva a los pueblos andinos de historicidad y agencia, ocultando -por ejemplo- su activa participación en los procesos de modernización del territorio ${ }^{2}$.

En esta perspectiva, proponemos -siguiendo las reflexiones de Poole (2000)- que el acto de ver y representar interviene o crea el mundo; lo que equivale a reconocer que las imágenes "han sido moldeadas para adecuarse a determinadas agendas políticas y culturales tanto de los agentes de la dominación imperial como de los nativos que se resisten (y adecuan) a este dominio" (Poole 2000:18). De este modo, nos importa explorar no tanto las imágenes construidas en torno o sobre los pueblos andinos; sino más bien, las relaciones socialmente específicas de producción y circulación de sus propios referentes imagéticos. Con lo cual aludimos a un régimen alternativo de visualidad, "en el cual el cuerpo vuelve a desbaratar la mirada desinteresada del espectador cartesiano desencarnado" (Poole 2000:29).

En este caso, referimos a las manifestaciones expresivas o performances sociales, particularmente fiestas y danzas andinas ${ }^{3}$, ya no como objetos de representación, sino como estrategias de autorrepresentación a través de las cuales los actores andinos han exhibido con vitalidad sus propias memorias y estéticas.

\section{Folclore Progresivo ${ }^{4}$ : Manifestaciones Expresivas Andinas en Arica}

A partir de un humanismo progresivo que, de acuerdo a De Martino (2008), ve al "mundo popular como un mundo humano en movimiento" (De Martino 2008:96), capaz de hacer historia y construir significados desde el presente; emprendemos el estudio de las manifestaciones expresivas andinas desde una perspectiva que sitúa la agencia indígena y popular en la construcción de propios modelos perceptivos y de representación, y reconocemos en las performances la actualización y transmisión de una memoria corporalizada, que se fundamenta en un trabajo de recreación de repertorios, identidades y subjetividades (Taylor 2015).

En principio, podemos afirmar que si bien fiestas y danzas andinas se realizan profusamente en la cordillera y altiplano chilenos -lo que coincide con la sobrerrepresentación a la que hemos aludido-, se trata de prácticas que no son exclusivas de los pueblos rurales. Más bien, y a partir de los procesos de migración aymara, desde la cordillera de los Andes hacia las ciudades costeras del Norte Grande de Chile (región de Tarapacá) en la década de 19605, la participación ritual y festiva será potenciada -e inclusive organizada- desde las ciudades ${ }^{6}$; siendo central en la construcción y mantención de referentes identitarios con los pueblos de origen. De esta manera, tenemos que las estrechas relaciones campo-ciudad no solo se expresarán en la mantención de vínculos socioeconómicos con la cordillera (comercio, producción agroganadera, envío de remesas, entre otros) (González 1995); sino también a través de la gestión urbana-rural de fiestas y celebraciones comunitarias (cf. Chipana 1986; Gavilán y Carrasco 2009; González 2003; González y Gavilán 1990; González y Gundermann 1996; Grebe 1986; Tabilo et al. 1995).

En un mismo proceso, se ha observado que la creación de organizaciones económicas, sociales y culturales aymara en las ciudades no solo mejoró las condiciones de inserción e integración, permitiéndoles obtener derechos y legitimidad ante el Estado (Gundermann y Vergara 2009); sino que potenció el desarrollo de una colectividad andina que "conquista el espacio urbano a través de fiestas familiares y comunales" (Zapata 2001:62). Territorio simbólico 
que en el caso de la comuna de Arica (valle de Azapa y Arica), ha cristalizado en la celebración anual de fiestas andinas, cuyo ciclo contempla: Fiesta de Todos los Santos, Cruces de Mayo, Machaq Mara, Martes de ch'alla y Carnavales, entre otras.

Actualmente, al igual que en otras ciudades del área surandina donde las prácticas o manifestaciones expresivas andinas (fiestas, danzas y música) han demostrando constituir mecanismos de comunicación, reconocimiento e interacción intercultural ${ }^{7}$; en Arica, el Carnaval Inti Ch'amampi, "Con La Fuerza del Sol" (en adelante Carnaval Inti Ch'amampi), que es fruto de la gestión y trabajo mancomunado de agrupaciones de bailes andinos, ha logrado resignificar el carácter de las relaciones e intercambios económicos y culturales en un espacio socialmente heterogéneo y transfronterizo (Chamorro 2013).

En este contexto, y a partir de materiales y análisis etnográficos realizados entre los años 2009-2010 y 2012-2015 en torno a esta fiesta ${ }^{8}$, sugerimos explorar las danzas andinas del Carnaval Inti Ch'amampi como estrategias performáticas de comunicación y autorrepresentación a través de las cuales los grupos subalternos responden a las imágenes impuestas (Cánepa 2001)9 . En este sentido, revisamos el concepto teórico y metodológico de performance para aproximarnos a sus estrategias visuales de producción o creación; así como a las experiencias y significados dados a la exhibición y transmisión de memorias corporalizadas.

Dimensiones de un "folclore progresivo" con el cual buscamos construir una mirada centrada en los sentidos de los "sujetos creadores de historia" (De Martino 2008:93), así como en un proceso de creación arística que hace "un uso renovado de cada elemento válido y activo" (De Martino 2008:97) de la tradición, para resonar con voz presente.

\section{Performance como autorrepresentación}

El concepto de performance, pese al peligro de legitimar las relaciones de poder que el término anglosajón connota ${ }^{10}$, alude simultáneamente a "un proceso, una práctica, una episteme, un modo de transmisión, una realización y un medio de intervenir en el mundo" (Taylor 2007); que excede las posibilidades que ofrecen otras nociones, pues discute y/o complementa el logocentrismo de la cultura como texto desde una práctica corporalizada.

Teóricamente, de acuerdo con Schechner (2000), refiere a "actividades que no se realizan por primera vez sino por segunda vez y ad infinitum" (Schechner 2000:13), y aunque es imprescindible precisar que ninguna repetición es exactamente lo que copia pues los sistemas están en flujo constante; se trata de "cintas de conductas" que existen aparte de los actores que las realizan, por lo que se pueden guardar, transmitir, manipular y transformar (Schechner 2000). Vale decir, se trata de "repertorios de memorias corporizadas" que, de acuerdo con Taylor (2015), constituyen medios vitales de acumulación y transmisión de saber social y sentidos de identidad. En este sentido,

\section{las genealogías de performance se constituyen a partir de la idea de que los movimientos expresivos son reservas mnemónicas, e incluyen movimientos concertados que se realizan y recuerdan con el cuerpo (Joseph Roach citado por Taylor 2011:22).}

Las performances proponen que "la memoria colectiva se realiza entonces en el presente, es decir, en el momento en que un sujeto comunica a otro un hecho pasado" (Cánepa 2001:14). Tenemos que los/as actuantes (performers) no realizan una puesta en escena, más bien son conscientes de ser partes de un acto comunicativo, "poniendo a juicio de la audiencia tanto la performance como a sí mismos, en tanto agentes de la representación" (Cánepa 2001:17). Cualidad que, para Cánepa (2001), presenta la imposibilidad de "mantener la distinción entre el medio y el mensaje; es decir, entre el cuerpo como medio de la representación y el cuerpo objeto de la representación" (Cánepa 2001:18). Modelo de autorrepresentación que, por lo demás, apela a un código abierto que permite generar prácticas y significados culturales, que podrían ser utilizados con fines contrahegemónicos o bien como mecanismos de autoconstitución o transformación (Citro 2009).

\section{El Carnaval Andino en Arica}

El origen del Carnaval "Inti Ch'amampi" se encuentra asociado a los procesos de migración e instalación de familias aymara provenientes de las vertientes chilena y boliviana de la cordillera de los Andes, en Arica y el valle de Azapa. En este contexto, y con el fin de comprender el carácter de las representaciones performáticas que emergen de esta fiesta debemos distinguir las dináminas 
festivas desplegadas por ambas poblaciones (cf. Grebe 1986). Pues mientras los aymara chilenos mantuvieron una vinculación ritual con sus pueblos de origen, a través de la participación y actualización de sus calendarios festivos; los aymara bolivianos tendieron a actualizar sus tradiciones festivo-rituales en los espacios de acogida, siendo las tarqueadas ${ }^{11}$ una de las primeras expresiones que músicos y bailarines, provenientes de diversas localidades del Departamento de Oruro (Bolivia), que se organizaron con el objetivo de celebrar los carnavales en el valle de Azapa (Figura 1).

Hacia la década de 1970, las organizaciones migrantes andinas introducirán los sonidos y danzas del folclore urbano boliviano como estrategia de integración de las nuevas generaciones; y, a fines de la década de 1980 se presentarán por primera vez en la competencia folclórica de la Ginga, fiesta cívica-o de primavera-que se realizaba anualmente en Arica ${ }^{12}$. Hito que marca el comienzo de una intensa experiencia de crecimiento y autonomía como organizaciones andinas, que les permitirá construir las condiciones sociales y performáticas (participación con bandas de bronces y empleo de trajes folclóricos) para su visualización y aceptación pública, guiándolos a crear el Carnaval "Inti Ch'amampi" (cf. Chamorro 2013)13.

Y lo que nosotros hemos querido hacer es prevalecer en el carnaval, mostrar lo que tienen los pueblos y ha quedado acá en Chile, lo que gente algún día negó, los gobiernos negaron y están vivos, son pocos pero están vivos, mostrar lo que ellos hacen, lo que ellos viven, acá en el carnaval ellos no bailan, ellos muestran lo que ellos hacen, cómo ellos viven (Bailarín y dirigente, Tobas Andino Sajama).

Así como podemos advertir que para aymara bolivianos y chilenos, los sentidos del carnaval se asocian a una tradición agrofestiva originada en la cordillera andina, donde esta celebración renueva el tiempo y propicia la fertilidad de la vida (tierra, humanos y animales) (Alvarado y Mamani 2007; Gavilán y Carrasco 2009), a través de gestos y símbolos performáticos (Sigl 2009). En el contexto urbano de Arica observamos que

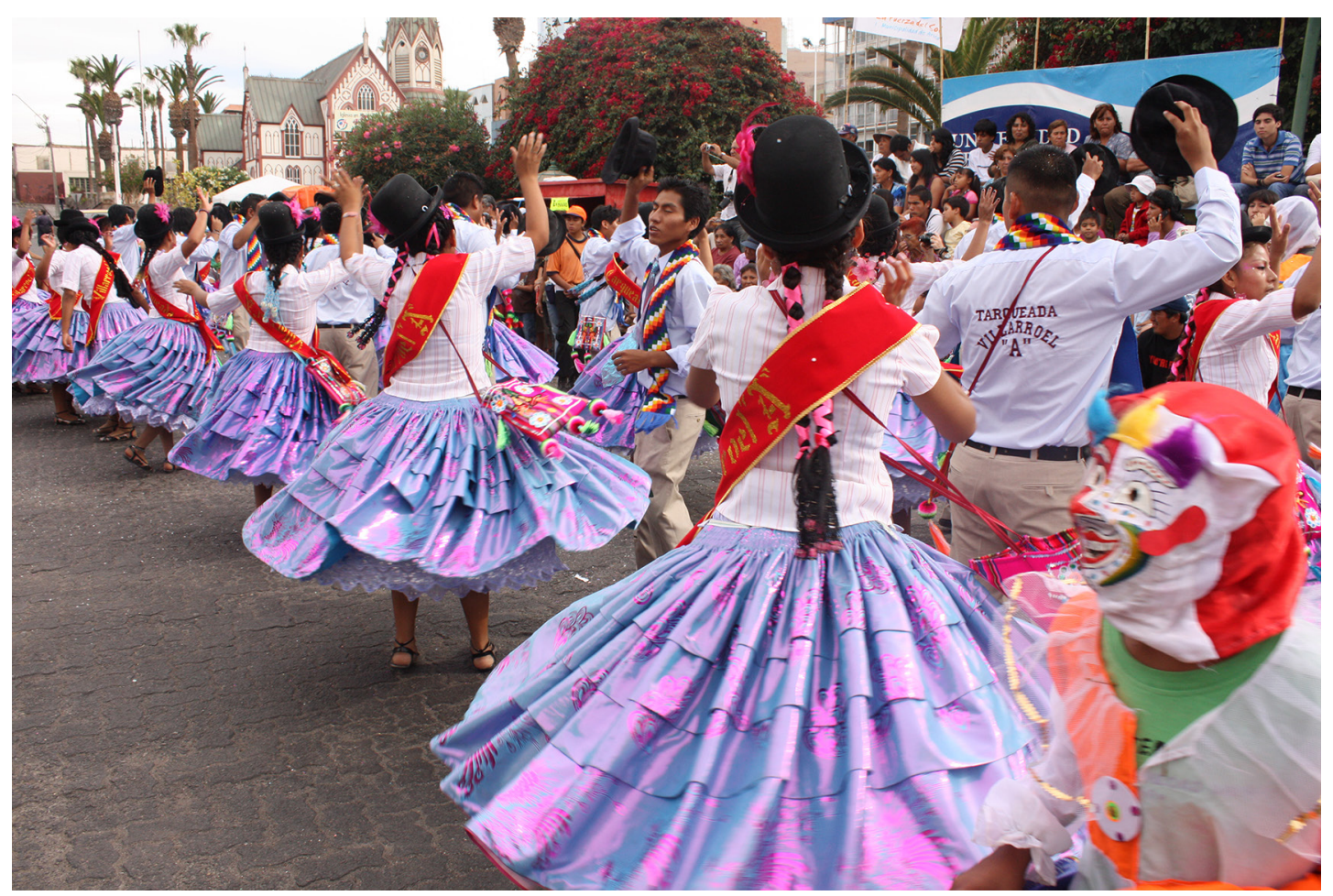

Figura 1. Tarqueda Villarroel "A”, fundada en 1968. Fuente: Donoso 2010.

Tarqueda Villarroel “A”, founded in 1968. Source: Donoso 2010. 
la composición familiar de las organizaciones así como sus dinámicas de recreación festiva (ensayos de baile, ceremonias, entrada de carnaval, entre otros) también constituyen "espacios de cohesión donde ha sido posible reproducir social y simbólicamente relaciones ligadas a una herencia cultural andina" (Chamorro 2013:48). En este sentido, el carnaval es considerado una plataforma pública que, a contrapelo de las diferencias nacionales, es concebida como un espacio de integración que tiende a la consolidación de relaciones transfronterizas andinas y a la "unidad del pueblo aymara"14.

En este escenario ${ }^{15}$, comprender la noción de performance como estrategia de autorrepresentación en un espacio público y transfronterizo, apela al acto de construir, transmitir y exhibir una imagen corporizadada que remite a una "herencia" y memoria andina compartida, así como a la manifestación "vivida" de particulares sentimientos y emociones festivas.

\section{Danza-trajes-música como autorrepresentación festiva}

En tanto que memoria y saberes corporizados, el danzar no solo otorga vida y movimiento a la imagen del/la danzante ataviado/a de trajes e indumentaria, sino que indica que es este/a quien construye y transmite sus significados a una audiencia diversa. En consonancia, recogemos algunas de las categorías empleadas por bailarinas/es andinos que, en torno a la preparación y desarrollo del Carnaval Inti Ch'amapi, aluden a sus prácticas de autorrepresentación. Así, proponemos que referencias tales como: "mostrar" o "mostrarse", "lucir" o "lucirse", o bien "sacar la cara por el pueblo"; constituyen definiciones de performance, que en tanto categorías visuales de prácticas corporalizadas, connotan una intención comunicativa que podemos reconocer en varios planos del escenario material y simbólico de la fiesta.

En primer lugar, la "Entrada del Carnaval"16, que refiere al desfile de las diversas agrupaciones de baile por las calles del centro histórico de ciudad en dirección al "Morro de Arica"17 (Figura 2); condensa las aspiraciones y emociones de los actuantes en torno a los trabajos de preparación corporal y escénica que han realizado a lo largo del año. Por lo que la experiencia de desplazamiento, donde son vistos, seguidos e interpelados por una multitud heterogénea de espectadores; refuerza la noción de que los bailes permiten sobresalir y expresar belleza, generando sentimientos de orgullo y distinción social que dialoga con una audiencia local, nacional e internacional. A modo de ejemplo, la gira promocional del Carnaval Andino del Bicentenario 2010 que se hizo en la zona centro-sur del país llegando hasta el palacio de La Moneda (tribuna de legitimación institucional y simbólica por antonomasia), uno de los dirigentes aymara indica:

es un logro que la presidenta haya mirado nuestro baile originario, ella lo bailó con nosotros y para nosotros es un logro como pueblo, que la presidenta haya bailado -en ese pequeño instante- el baile con nosotros (Bailarín y dirigente, Tobas Andino Sajama).

Asimismo, estas categorías performáticas también aluden a un sentido de prestigio social, asociado a una idea de exaltación que se alcanzaría a través del carácter competitivo del Carnaval. Cabe argumentar, siguiendo las reflexiones de DaMatta (2002), que como mecanismo autonómo de reclasificación social, la competencia ofrece posibilidades de democratizar los recursos materiales y simbólicos que la sociedad hegemónica escamotea. Importando constrastar estos significados asociados a un modelo de interés individual propio de la modernidad occidental, respecto de su afinidad con los sentidos de la competencia en el marco de las fiestas y danzas andinas autóctonas, donde la asimetría anima y entretiene, así como ordena y recrea la sociedad y la vida de las personas (Ortiz 2009).

En todas las agrupaciones se busca su prestigio, todas las agrupaciones tratan de ganar su prestigio. Por qué, porque... tú cuando ganas el carnaval o ganas un campeonato mejor, siempre los Tinkus Mallku ganan su prestigio ellos, por qué, porque ellos ganaron un campeonato y venía el carnaval y ganaron el carnaval, y ¿de qué sirve eso de tener prestigio?, vas con la frente en alto como agrupación (Bailarina y Ñusta, Tinkus Kollas Wistus).

Por lo demás, el prestigio también participa de un sistema de valores sociosimbólicos donde la antigüedad de la agrupación, la exhibición de trajes costosos, el contrato exclusivo de bandas de bronce con demostrada trayectoria y calidad musical, entre 


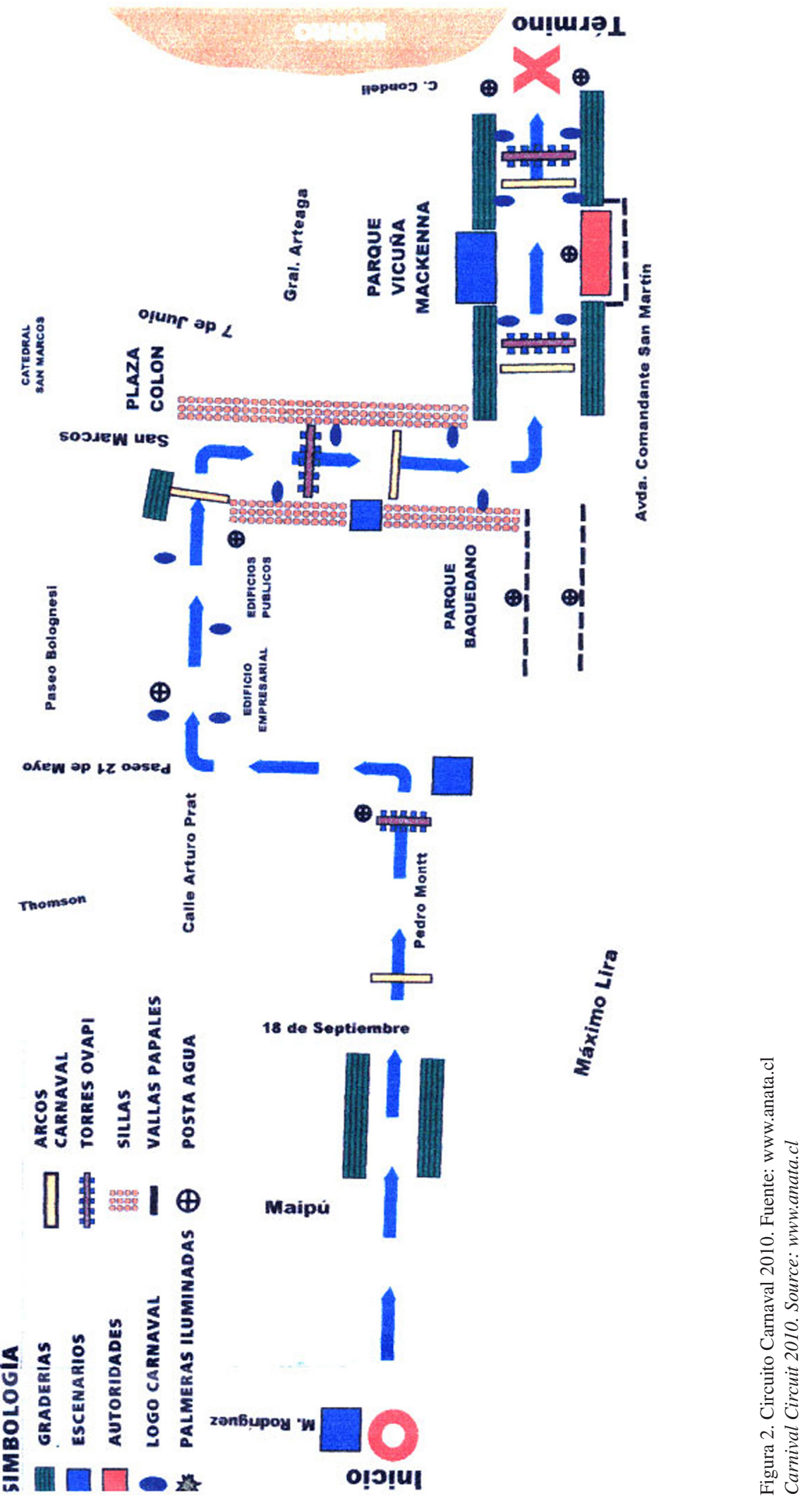


otros signos, permiten ostentar el acceso económico a bienes estéticos en el contexto de la communitas ${ }^{18}$ andina que se recrea en torno a la fiesta (Tassi 2010) ${ }^{19}$. Dimensión que permite resemantizar las jerarquías y/o exclusiones sociales (Cárdenas 2009), a la vez que conectar con una "estética de la abundancia y multiplicación" que, de acuerdo a Sigl (2011), caracteriza a las danzas rurales en su relación con la naturaleza (p.ej. empleo de plumas y polleras multicolores) y es perpetuada en contextos urbanos a través de la profusión de índices de riqueza como joyas de oro, sombreros de paño, tejidos de lana de vicuña, bordados artesanales, entre otros (Figura 3 ).

Siguiendo estas coordenadas, sugerimos que bailes, trajes y música constituyen mecanismos expresivos de autorrepresentación mediante los cuales los grupos subordinados diseñan sus propios modelos descriptivos (Cánepa 2001). Repertorios que, a la manera de una tríada, coforman "escenografías en movimiento" (Barba y Savarese 2010) que contribuyen a producir imágenes de sí mismos.

$\mathrm{Al}$ respecto, observamos que, por un lado, el traje o vestido festivo representa las "tradiciones" andinas, las cuales remiten a las prácticas festivorituales de los pueblos rurales de origen y/o a la celebración foclórica boliviana (mestiza, indígena urbana y/o popular andina). Un bailarín de tarqueada altiplánica precisa:

el carnaval de acá de Arica es para lucirse, es para lucirse y de repente se muestra el $70 \%$ de lo que se baila en el pueblo, porque usted acá baila con zapato, y allá en ese tiempo se bailaba con chalas o, ojotitas qué se yo, tradición de allá (Bailarín, Agrupación Hijos de Caquena).

Por otro lado, importa advertir que el traje, como materialidad, es fruto de una negociación y acuerdo en temas de diseño, texturas y colores, que mantienen los/as bailarines/as junto a los "bordadores" (artesanos especializados en indumentaria festiva) en torno a la innovación e identidad de cada una de las danzas; motivo por el cual emergen bailes de "caporales" con los colores de la bandera chilena o "chinas" decoradas con la imagen del "picaflor de Arica", por poner algunos ejemplos (Figura 4).

En todos los casos observados, la imagen corporizada del/la danzante remite a una memoria o "herencia" compartida que le permite comunicar y vivenciar sus propios imaginarios de identidad.

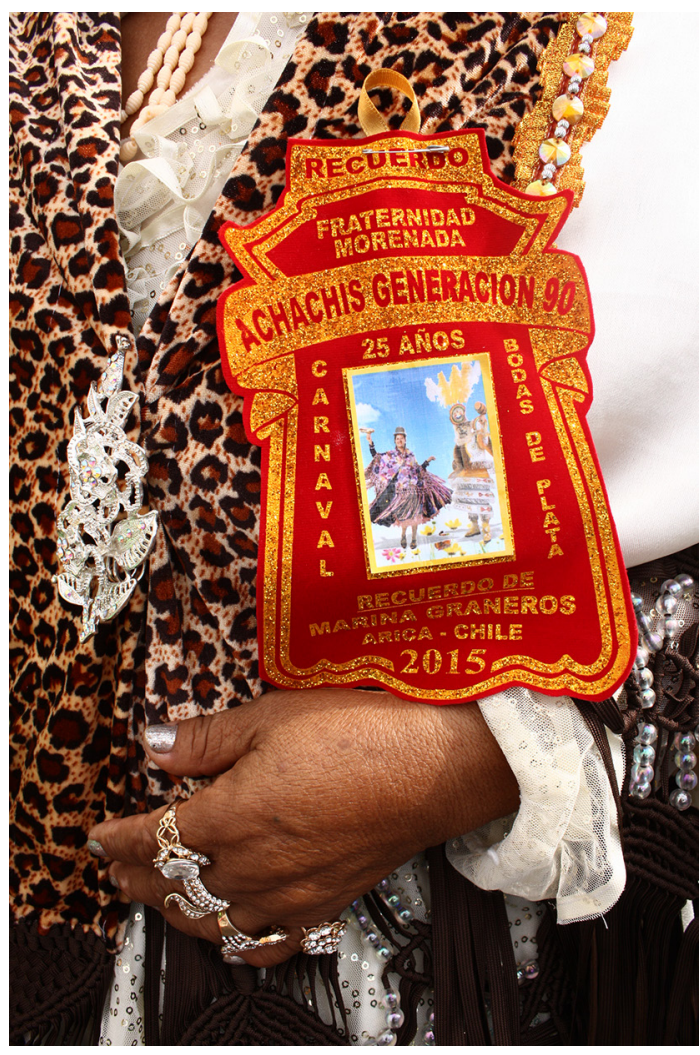

Figura 3. Detalle "cholita", Fraternidad Morenada Achachis Generación 90. Fuente: Chamorro 2015.

Detail "cholita", Fraternity Morenada Achachis Generación 90. Source: Chamorro 2015.

\section{Bailar con el "corazón”}

El aprendizaje de las danzas andinas se asocia a una transmisión de conocimientos prácticos que se produce fundamentalmente por imitación durante la participación en fiestas y rituales, constituyendo "esferas de socialización de gran carga significativa e impacto emotivo para las nuevas generaciones" (Borea 2008:86). Asimismo, los sentidos étnicos y estéticos que son corporizados por los/as bailarines/ as al danzar, también se producen en espacios de entrenamiento corporal como los ensayos de baile, donde el aprendizaje y ejecusión de las danzas va directamente asociada a la interiorización de la música.

Cuando uno entra a bailar, cuando uno escucha a la banda, siente que se le olvidó todos sus problemas, todo lo que te duele, que la banda es ritmo, que tú escuchas la 


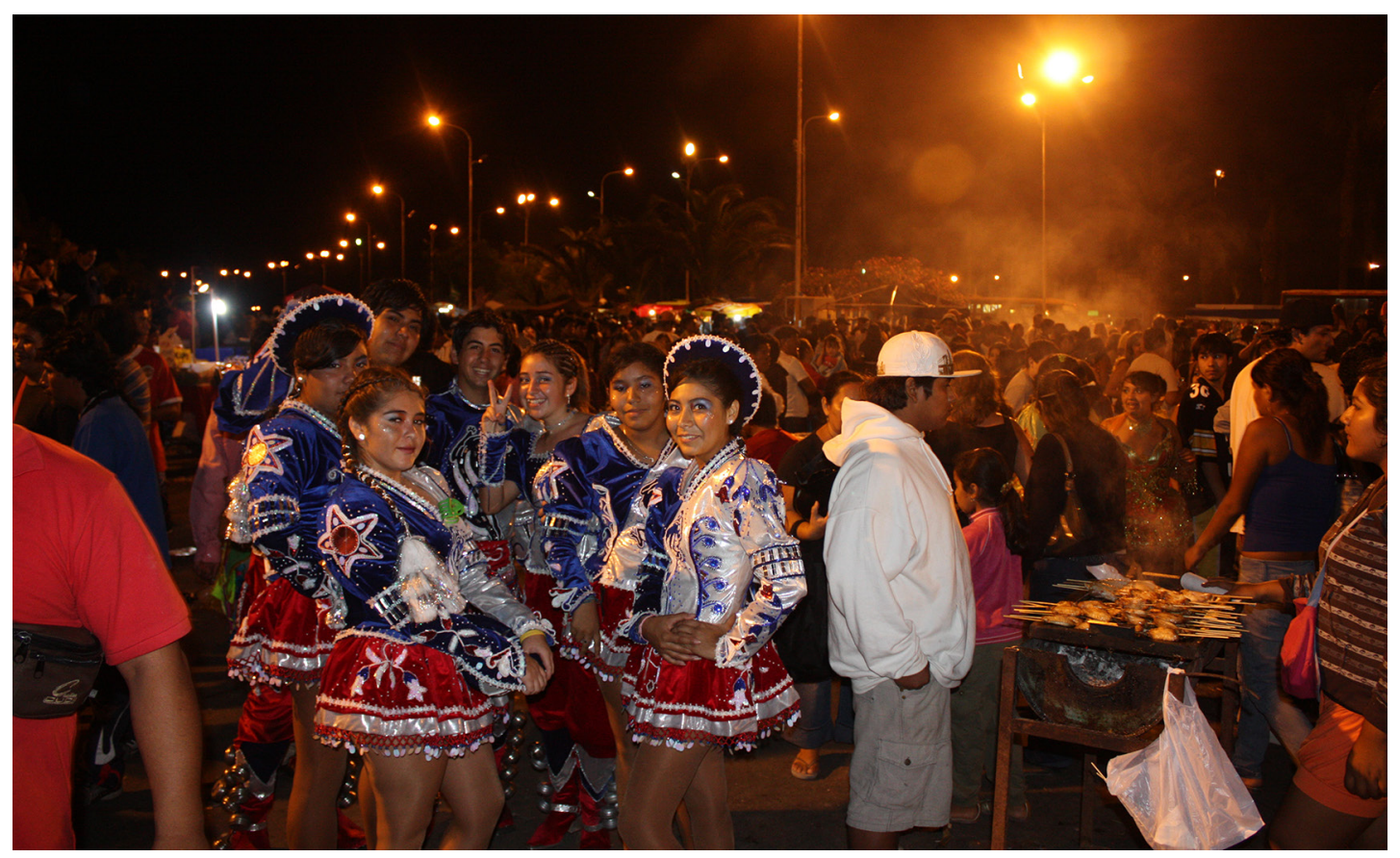

Figura 4. Traje tricolor de caporales. Fuente: Donoso 2010. Tricolor caporales'dress. Source: Donoso 2010.

banda es ritmo, tum, tum, el bombo y hace como te hace el corazón tum, tum, tum, te dan ganas de bailar (Bailarina, Tinkus Kollas Wistus).

No obstante, observamos que el bailar se asocia a la posibilidad de expresar "pasión y sentimiento" por la música y danza andinas, lo cual alude a un complejo de emociones que se ubican físicamente en el corazón. Siguiendo este sitio y gesto corporal, los bailarines/as y/o descendientes aymara entrevistados, señalan que el ritmo musical "se lleva en la sangre" o es un "sentimiento que corre por las venas"; lo cual no solo permite comprender que el danzar produce una serie de sensaciones sinestésicas y nmemónicas. Sino que -y fundamentalmente- el "mostrarse" y "lucirse" durante el carnaval implica el "sentirse" y "vivirse" performáticamente como "andinos" (Figura 5).

El carnaval en sí es como que ya terminamos un ciclo, vamos a empezar una nueva vida y a eso hay que darle un poco de emoción, un poco de festividad, un poco de alegría y eso es el carnaval para nosotros, no es una puesta en escena, sino que es un sentimiento (Bailarín y dirigente, Tobas Andino Sajama).

\section{Conclusiones}

En la perspectiva de que el Carnaval Inti Ch'amampi constituye una performance o "cinta de conducta" que es actualizada por los bailarines/ as andinos; sugiero que el "mostrar", "lucir", "sacar la cara por el pueblo", constituyen categorías visuales que aluden al acto performático de exhibir y transmitir la propia memoria y valores estéticos entre una colectividad festiva andina o communitas, así como entre una audiencia heterogénea.

Comunicación de códigos visuales, corporales y sonoros que construyen un territorio simbólico que actualiza la relación translocal y transnacional con la cordillera y altiplano chileno y boliviano, a la vez resignifica el espacio urbano.

De esta manera, la proyección reiterativa -performática- de una imagen corporalizada contesta a la invisilidad y supuesta atemporalidad de las representaciones sociales y visuales de los pueblos andinos; sugiriendo que danzas-trajes-música, en tanto "régimen alternativo de visualidad", constituyen 


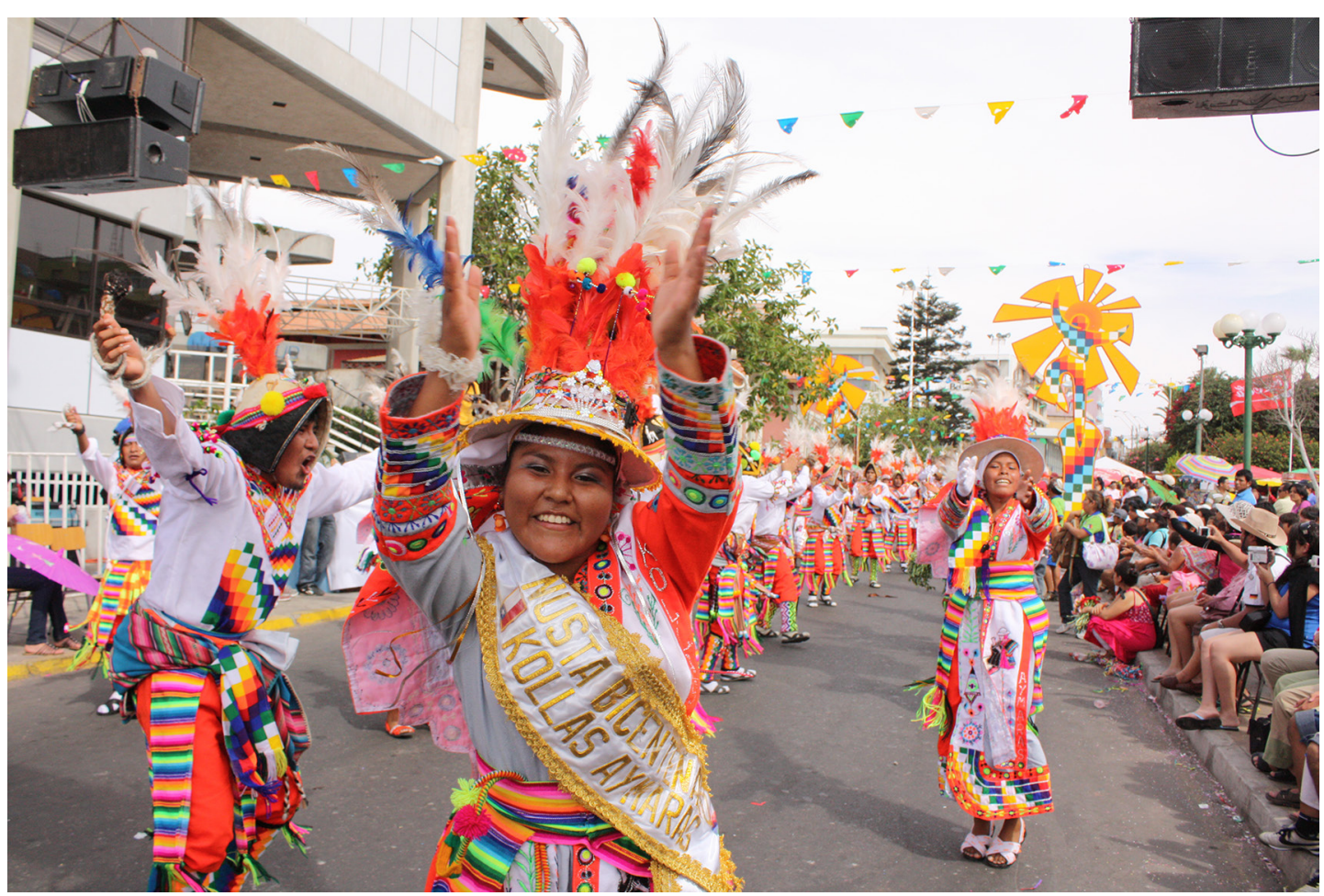

Figura 5. Tinkus sobre calle San Marcos. Fuente: Donoso 2010.

Tinkus on Calle San Marcos. Source: Donoso 2010.

una clave que revierte y problematiza la colonialidad de nuestra mirada.

Agradecimientos: Este artículo es resultado del proyecto Mayor de Investigación Científica y Tecnológica 2015 de la Universidad de Tarapacá, código 3710-15: "Cuerpo en fiesta: circulación transfronteriza y significado del traje en las danzas del carnaval andino en Arica". Mis agradecimientos a los evaluadores de Chungara, pues sin duda sus observaciones contribuyeron a enriquecer estas reflexiones. Agradezco también el trabajo comprometido de Nathaly Ardiles y Karina Sepúlveda, asistentes de investigación, y de Juan P. Donoso, antropólogo responsable del registro audiovisual de danzas y trajes. Junto con ellos, agradezco a los bailarines/as aymara, en quienes se fundamenta e inspira esta propuesta, "mis brazos se alzan y mis pies que van corriendo / mis labios gritan gracias, gracias...".

\section{Referencias Citadas}

Abercrombie, T. 1992. La fiesta del carnaval postcolonial en Oruro: Clase, etnicidad y nacionalismo en la danza folklórica. Revista Andina 10:279-352, Cusco.

Alvarado, M., P. Mege, M.P. Bajas y C. Möller (eds.) 2012. Andinos. Fotografías Siglos XIX y XX. Visualidades e Imaginarios del Desierto y el Altiplano. Pehuén Editores, Santiago.

Alvarado, M. y M. Mamani (eds.) 2007. Capítulo 2. El origen de la "Ispalla" - Carnaval Andino o Anata. En El Origen de las Fiestas Andinas, pp. 30-40. Centro de Integración e Investigación en Historia Oral Andina y Medicina Ancestral, La Paz.
Alvarado, M. y C. Möller 2012. Fuera de Cuadro. Representación y alteridad en la fotografía del indígena del desierto y el altiplano. En Andinos. Fotografías Siglos XIX y XX. Visualidades e Imaginarios del Desierto y el Altiplano, editado por M. Alvarado, P. Mege, M.P. Bajas y C. Möller, pp. 23-40. Pehuén Editores, Santiago.

Báez, C. y A. Castro 2012. El indígena del norte grande y su representación visual en la historia de Chile. Pasado y presente de una relación confusa. En Andinos. Fotografías Siglos XIX y XX. Visualidades e Imaginarios del Desierto y el Altiplano, 
editado por M. Alvarado, P. Mege, M.P. Bajas y C. Möller, pp. 69-86. Pehuén Editores, Santiago.

Barba, E. y N. Savarese 2010. El Arte Secreto del Actor. Diccionario de Antropología Teatral. Editorial San Marcos, Lima.

Barragán, R. 2009. Primera parte. La fiesta del poder, el poder de la fiesta. En Gran Poder: La Morenada, editado por R. Barragán y C. Cárdenas, pp. 15-258. Instituto de Estudios Bolivarianos, La Paz.

Bastien, J. 2004. Las danzas foklóricas en las entradas de Bolivia: pachamama and chora. En Quechua Verbal Artistry: The Inscription of Andean Voices. Arte Expresivo Quechua: La Inscripción de las Voces Andinas, editado por G. Delgado-P y J.M. Schechter, pp. 537-570, Institut für Altamerikkanistik und Ethnologie, Bonn.

Benza, S. 2009. Procesos de enseñanza no formal de la danza peruana entre migrantes peruanos en Buenos Aires. Anthropologica 27:75-91.

Borea, G. 2008. Nuevas generaciones y continuidad ritual. En Fiesta en los Andes. Ritos, Música y Danzas del Perú, editado por R. Romero, pp. 72-101, Fondo Editorial Pontificia Universidad Católica del Perú, Lima.

Cánepa, G. 2001. Identidades Representadas. Performance, Experiencia y Memoria en los Andes. Fondo Editorial Pontificia Universidad Católica del Perú, Lima.

Cárdenas, C. 2009. Segunda parte: El poder de las polleras. Performatividad, representación y poder entre las bailarinas de morenada del Gran Poder. En Gran Poder: La Morenada, editado por R. Barragán y C. Cárdenas, pp. 259-418. Instituto de Estudios Bolivarianos, La Paz.

Carreño, G. 2005. Pueblos indígenas y su representación en el género documental: una mirada al caso aymara y mapuche. Revista Austral de Ciencias Sociales 9:85-94.

Chamorro, A. 2013. Carnaval Andino en la ciudad de Arica: performance en la frontera norte chilena. Estudios Atacameños 45:41-54.

Chipana, C. 1986. La identidad étnica de los aymaras en Arica. Chungara 16-17:251-261.

Citro, S. 2009. Cuerpos Significantes. Travesías de una Etnografía Dialéctica. Editorial Biblos, Buenos Aires.

DaMatta, R. 2002. Carnavales, Malandros y Héroes. Hacia una Sociología del Dilema Brasilero. Fondo de Cultura Económica, México, D.F.

De Martino, E. 2008. El Folclore Progresivo y Otros Ensayos. Museu d'Art Contemporani de Barcelona, Barcelona.

Gavilán, V. y A. Carrasco 2009. Festividades andinas y religiosidad en el norte chileno. Chungara Revista de Antropología Chilena 41:101-112.

González, H. 1995. La inserción económica de los migrantes aymara en la ciudad. El trabajo como empresa familiar y la reproducción cultural. Actas del Segundo Congreso Chileno de Antropología, Tomo I, pp. 315-324, Colegio de Antropólogos de Chile, Valdivia.

González, H. 2003. Los aymaras contemporáneos. En Conozcamos Juntos la Historia y Cultura de Nuestra Región, editado por A.M Carrasco y B. Cofré, pp. 39-45. Taller de Estudios Andinos,
Gobierno Regional de Tarapacá, Conicyt-Explora y Centro de Investigaciones del Hombre en el Desierto (CIHDE), Arica.

González, H. y V. Gavilán 1990. Cultura e identidad étnica entre los aymaras chilenos. Chungara 24/25:145-158.

González, H. y H. Gundermann 1996. Organizaciones aimaras, identidad étnica e integración. En La Integración Surandina Cinco Siglos Después, compilado por X. Albó, M. I. Arratia, J. Hidalgo, L. Núñez, A. Llagostera, M.I. Remy, B. Revesz, pp. 395-416. Centro Bartolomé de Las Casas, Corporación Norte Grande Taller de Estudios Andinos, Universidad Católica del Norte, Antofagasta.

Grebe, M.E. 1986. Migración, identidad y cultura aymará: Puntos de vista del actor. Chungara 16-17:205-223.

Gundermann, H. 1997. Etnicidad, identidad étnica y ciudadanía en los países andinos y el norte de Chile. Los términos de la discusión y algunas hipótesis de investigación. Estudios Atacameños 13:9-26.

Gundermann, H. y J.I. Vergara 2009. Comunidad, organización y complejidad social andinas en el norte de Chile. Estudios Atacameños 38:107-126.

Harris, O. 1983. Los muertos y los diablos entre los Laymi de Bolivia. Chungara 11:135-152.

Instituto Nacional de Estadísticas [INE]. 2002. Estadísticas Sociales de los Pueblos Indígenas en Chile. MIDEPLAN/ BID, Santiago.

López, U. 2007. Anata Andino. Máscaras y Danzas de los Ayllus de Oruro. CEPA, Oruro.

Martínez, G. 1996. Saxra (Diablo) / Pachamama: música, tejido, calendario e identidad entre los jalq'a. En Cosmología y Música en los Andes, editado por M. Baumann, pp. 283-310, Iberoamericana, Madrid.

Modenesi, M. 2010. Capítulo I. Subalternidad. En Subalternidad, Antagonismos, Autononía. Marxismos y Subjetivación Política, pp. 25-52, CLACSO, Buenos Aires.

Nash, J. 2008. El orden natural y sobrenatural. En Comemos a las Minas y las Minas nos Comen a Nosotros. Dependencia y Explotación en las Minas de Estaño Bolivianas, pp. 153-200. Antropofagia, Buenos Aires.

Ortiz, A. 2009. El contrapunteo festivo: el contrapunto y la competencia en las fiestas andinas. Perspectivas Latinoamericanas 6:162-171.

Podestá, J. 2004. La Invención de Tarapacá. Estado y Desarrollo Regional en Chile. Ediciones Campus, Universidad Arturo Prat, Iquique.

Poole, D. 2000. Visión, Raza y Modernidad. Una Introducción al Mundo Andino de Imágenes. Casa de Estudios del Socialismo, Lima.

Restrepo, E. y A. Rojas 2010. Inflexión Decolonial, Fuentes, Conceptos y Cuestionamientos. Instituto de Estudios Sociales y Culturales, Universidad Javeriana Editorial Universidad del Cauca, Popayán.

Romero, R. 2008. Prólogo. En Fiesta en los Andes. Ritos, Música y Danzas del Perú, editado por R. Romero, pp. 1-13. Instituto de Etnomusicología, Fondo Editorial Pontificia Universidad Católica del Perú, Lima. 
Sabella, A. 1959. Norte Grande. Novela del Salitre. Editorial Orbe, Santiago.

Schechner, R. 2000. Performance. Teoría y Prácticas Interculturales. Secretaría de Extensión Universitaria y Bienestar Estudiantil, Universidad de Buenos Aires, Buenos Aires.

Sigl, E. 2009. Donde papas y diablos bailan. Danza, producción agrícola y religión en el altiplano boliviano. Maguaré 23:303-341.

Sigl, E. 2011. Cuando mujeres se visten de flores y chacras bailan. Danza, fertilidad y espiritualidad en el altiplano boliviano. Anthropos 106:475-492.

Tabilo, K., F. Venegas y H. González 1995. Las agrupaciones de residentes aymara urbanos en el norte de Chile: Adaptación a la ciudad y vínculos con las comunidades de origen. Serie de Documentos de Trabajo, Corporación Norte Grande, Arica.

Tassi, N. 2010. Cuando el Baile Mueve Montañas: Religión y Economía Cholo-Mestizas en La Paz, Bolivia. Fundación Praia, La Paz.

Taylor, D. 2007. Hacia una Definición de Performance. http:// performancelogia.blogspot.com/2007/08/hacia-una-definicinde-performance.html (12 mayo 2010).
Taylor, D. 2011. Introducción. En Estudios Avanzados de Performance, editado por D. Taylor y M. Fuentes, pp. 7-30. Fondo de Cultura Económica, México, D.F.

Taylor, D. 2015. El Archivo y el Repertorio. La Memoria Cultural Performática en las Américas. Ediciones Universidad Alberto Hurtado, Santiago.

Tudela, P. 19940. Chilenización y cambio ideológico entre los aymaras de Arica (1883-1930). Intervención religiosa y secularización. Revista Chilena de Antropología 12:201-231.

Turino, T. 1992. De esencialismo a lo esencial: pragmática y significado de la interpretación de los sikuri puneños en Lima. Revista Andina 2:441-456.

Turner, V. 1988. El Proceso Ritual. Estructura y Antiestructura. Editorial Taurus, Madrid.

Zapata, T.C. 2001. Las Voces del Desierto: Identidad Aymara en el Norte de Chile. Dirección de Bibliotecas, Archivos y Museos (DIBAM), Centro de Investigaciones Diego Barros Arana, Ril Editores, Santiago.

\section{Notas}

1 Como conflicto armado, la Guerra del Pacífico (18791883), no solo significó anexar la economía del salitre (Departamento de Tarapacá, Perú), sino también implementar mecanismos militares, políticos, sociales y simbólicos de incorporación de las poblaciones sometidas (indígenas, afrodescendientes, mestizos y criollos peruanos) al ideario de la nación chilena. Proceso de control y disciplinamiento denominado “chilenización” (cf. González y Gundermann 1996; Gundermann 1997; Tudela 1994).

2 Alvarado et al. (2012) reconocen la "costumbre andina", asociada a los campamentos mineros, de retratarse en "tenida de domingo" y de atesorar retratos familiares, que "se guardan y, sobre todo, se heredan" (Alvarado et al. 2012:9); aspectos que llevan a pensar en la valoración y prestigio de estas imágenes para las propias poblaciones andinas.

3 En los Andes "la fiesta es un suceso que estructura y ordena la vida de sus protagonistas, un universo con significados que expresan visiones del pasado, vivencias del presente y aspiraciones ante el futuro" (Romero 2008:12). Constituyendo un escenario temporal y espacial que otorga significaciones a múltiples semióticas -la mayoría no verbales- (Martínez 1996), tales como la música y las danzas.

4 Recogemos la noción de "folclore progresivo", de la propuesta de investigación del antropólogo italiano De Martino (1951). Esta retoma la experiencia etnológica y folclórica soviética tras la "irrupción del mundo popular en la historia", y responde a la "etnología naturalista", cuyas descripciones, clasificaciones y explicaciones causales estarían más en conexión con los intereses coloniales o imperiales, que con la comprensión del hecho humano y su vocación transformadora.

5 En el marco de las políticas de desarrollo y modernización implementadas en Arica durante la década de 1950 y hasta 1973, la ciudad se transforma en un importante polo de atracción para migrantes andinos, quienes articulan su economía en torno a estos procesos (cf. González 2003; Podestá 2004).

6 Actualmente, según el Censo 2002, la población aymara representa el 7\% de la población indígena de Chile, correspondiendo a 48.501 personas. De estas, 38.072 residen en las ciudades de manera permanente (INE 2002).

7 Diversas investigaciones en torno a la expresión festiva de migrantes andinos en ciudades como Lima (Perú), Oruro y La Paz (Bolivia), y Buenos Aires (Argentina) las definen como estrategias autónomas de inclusión social que han garantizado su reconocimiento público (cf. Abercrombie 1992; Barragán 2009; Bastien 2004; Benza 2009; Nash 2008; Turino 1992; entre otros).

8 El trabajo de campo contempló la realización de entrevistas antropológicas a bailarines/as andinos y otros actores relevantes, descripciones fotográficas y audiovisuales en distintos contextos performáticos; $y$, fundamentalmente, la participación como bailarina en agrupaciones folclóricas.

9 En el entendido que las relaciones coloniales despojaron a las poblaciones indígenas "de sus patrones de expresión visual y plástica" (Restrepo y Rojas 2010:99); la "subalternidad", como experiencia y subjetividad, refiere a "la incorporación y aceptación relativa de la relación de mando-obediencia y, al mismo tiempo, su contraparte de resistencia y de negociación permanente" (Modonesi 2010:37).

10 Al respecto, Taylor (2007) propone el uso del término performance en español, esto es 'performático' que denota la forma adjetivada del aspecto no discursivo de performance, como lo son las acciones gestuales, visuales y sonoras.

11 López (2007) plantea que la tarqa es un instrumento musical exclusivo para ejecutar y bailar en la Anata, por lo que la tarqueada es un género musical y coreográfico compuesto por tropas (o grupos) de músicos y bailarines/as que se reúnen durante la celebración de carnavales. 
12 Imitando al Carnaval de Río (Brasil), se promovía la participación de las Juntas de Vecinos a la manera de las escuelas barriales de samba.

13 Importa advertir que la participación en el espacio público de la ciudad es también fruto de la capacidad de negociación con gobierno local, para quien el Carnaval constituye un recurso para el desarrollo turístico de la ciudad (cf. Chamorro 2013).

14 Sin embargo, ello debe responder a reclamos por autenticidad que ubican al pueblo rural como garante de la tradición, o bien a las danzas folclóricas como bienes patrimoniales bolivianos. Controversias que revelan "la compleja manifestación y construcción de identidades en un escenario de frontera en el cual, sin embargo, la mayoría de los/as bailarines/as reconoce una ascendencia boliviana y/o peruana, pero principalmente un origen aymara" (Chamorro 2013:52).

15 En términos metodológicos, la preponderancia del "escenario" es el estudio de las performances "demanda que pongamos atención al ambiente y a los comportamientos corporales como gestos, actitudes y tonos no reductibles a lenguaje" (Taylor 2015:67).

16 Las Entradas folclóricas "tienen el formato de las procesiones religiosas y de las entradas seculares en las que convergieron tradiciones españolas y seguramente también andinas" (Barragán 2009:29).

17 En este contexto, el "Morro de Arica", ícono de la conquista chilena tras la Guerra del Pacífico, es resignificado como Mallku o cerro sagrado por los/as bailarines/as andinos urbanos (cf. Grebe 1986); motivo por el cual, y antes de comenzar las celebraciones, se ofrece una phawa o "mesa ritual" con el fin de garantizar el buen desarrollo de la fiesta. 18 Para Turner (1988), communitas refiere a una comunidad liminal que se manifiesta como potencialidad.

19 El costo promedio de un traje, que es diseñado y confeccionado en talleres artesanales paceños (Bolivia), bordea los 200 a 500 dólares; a lo que suma el contrato de una banda de bronce (aerófonos) por un mínimo de 3.000 dólares, que varía y aumenta dependiendo de su trayectoria, calidad y prestigio. 